\title{
Plastic rotation and tension stiffening effect analysis in beams using photogrammetry
}

\section{Análise da rotação plástica e da contribuição do betão entre fendas em vigas usando fotogrametria}
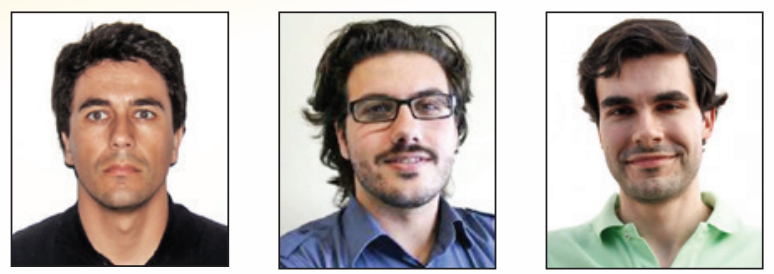

R. N. F. DO CARMO a carmo@isec.pt

J. VALENÇA ${ }^{b}$ jonatas@isec.pt

D. DIAS-DA-COSTA ${ }^{\circ}$ dias-da-costa@dec.uc.pt

\begin{abstract}
Innovative procedures for monitoring experimental tests using photogrammetry and image processing have been recently proposed. This manuscript aims at providing a practical demonstration of the advantages of using these new techniques in experimental tests up to failure. In this scope, focus is given to the curvature, rotation and to the tension stiffening effect, i.e., the contribution of the concrete between cracks to increase the bending stiffness. These parameters are crucial to describe the structural behavior of reinforced concrete beams both in serviceability and in ultimate limit states. These new techniques allow monitoring a high number of points, enhancing the traditional monitoring methods and providing more information which would be impossible to obtain using the traditional methods.
\end{abstract}

Keywords: curvature, plastic rotation, experimental tests, photogrammetry, image processing.

\section{Resumo}

A monitorização de ensaios experimentais tem registado desenvolvimentos significativos nos últimos anos mediante o recurso à fotogrametria e ao processamento de imagem. Neste artigo pretende-se demostrar a aplicabilidade prática destas novas técnicas na monitorização de ensaios até à rotura. Neste trabalho é dada especial atenção à curvatura, à rotação plástica e à contribuição do betão entre fendas para o aumento da rigidez à flexão, i.e., o "tension stiffening effect", os quais são fundamentais para caracterizar o comportamento estrutural de vigas de betão armado, tanto em serviço como em estado limite último. Verifica-se que estas novas técnicas permitem monitorizar um número muito elevado de pontos, complementando os métodos tradicionais de monotorização, e possibilitando a determinação de informação impossível de obter através dos métodos tradicionais.

Palavras-chave: rotação plástica, ensaios experimentais, fotogrametria, processamento de imagem.

\footnotetext{
CIEC, Instituto Superior de Engenharia de Coimbra, carmo@isec.pt, Rua Pedro Nunes - Quinta da Nora. 3030-199, Coimbra, Portugal; ICIST, Instituto Superior de Engenharia de Coimbra, jonatas@isec.pt, Rua Pedro Nunes - Quinta da Nora. 3030-199, Coimbra, Portugal; INESC, University of Coimbra, dias-da-costa@dec.uc.pt, Rua Luís Reis Santos, 3030-788 Coimbra, Portugal. School of Civil Engineering, The University of Sydney, NSW2006, Australia.
} 


\section{Introduction}

Monitoring experimental tests performed on structural elements is crucial to quantify the loading effects. Measuring forces, curvatures, displacements and strains in key sections allow characterizing the structural behavior of the element. The observation of the failure mechanism in reinforced concrete elements is also important simultaneously with the identification of the crack pattern. The above quantities are usually measured by traditional monitoring instruments, including: load cells, mechanical strain gauges, demecs, strain gauges and LVDTs.

Recently, new monitoring tools using photogrammetry and image processing were developed to determine some of the above parameters [1-8]. These tools allow to assess a large amount of data which is difficult, or even not possible, to measure with traditional methods. A detailed curvature evolution along the concrete beam axis is one example. This study aims at demonstrating how photogrammetry and image processing can be applied to study the flexural behavior of concrete beams and how these techniques go beyond the limitations of traditional methods. Furthermore, the analysis of the tension stiffening effect, combining the information obtained by photogrammetry and image processing, is presented.

\section{Plastic rotation and tension stiffening effect in reinforced concrete beams}

The possibility of achieving plastic analysis and linear analysis with moment redistribution requires a certain amount of plastic rotation in critical sections. It is important to ensure that critical sections can reach the foreseen failure type. In uncertain situations it becomes necessary to make an explicit verification of this capability. Thus, it is

\section{Figure 1 - Moment-curvature relation in a reinforced concrete section under pure bending before reinforcement yielding}

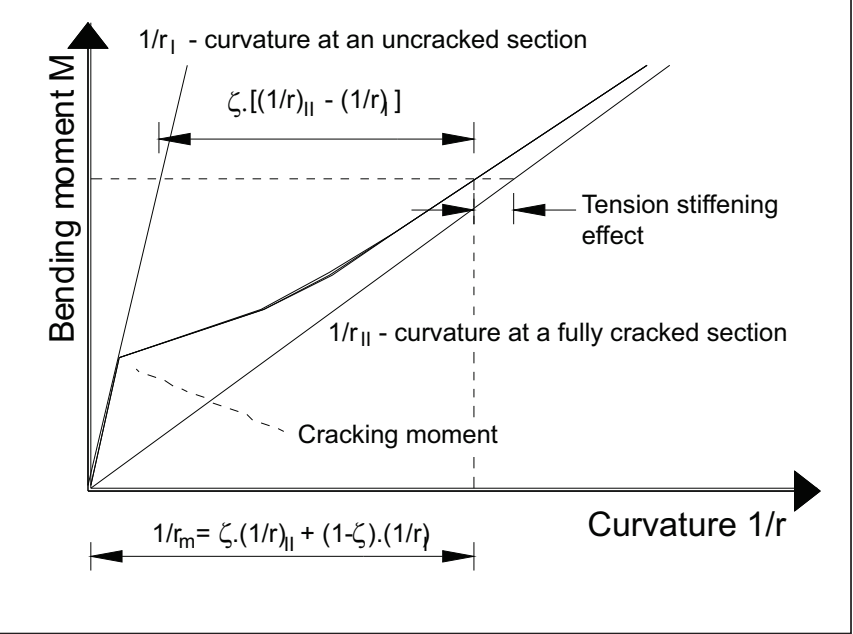

crucial to know the moment versus curvature relationship or, alternatively, plastic rotation capacity versus x/d parameter (see EC2 [9]). The plastic rotation capacity is defined as the difference between the rotation at the ultimate load and at the steel bars yielding onset. Therefore, the plastic rotation can be defined as the integral of the curvature after steel yielding in the plastified area (Eq. 1).

\section{Figure 2 - Curvature evolution and tension stiffening effect (example of a region under support)}

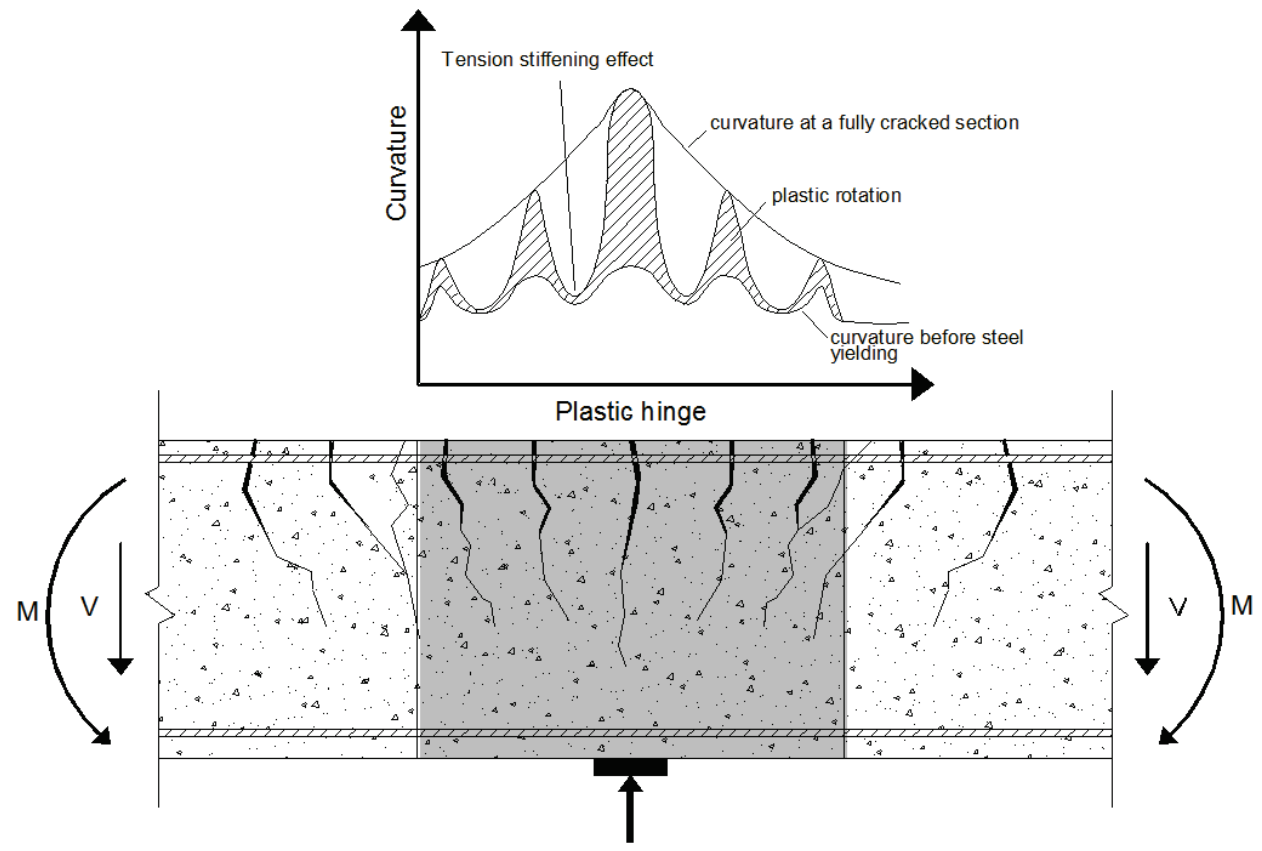




$$
\theta_{p l}=\int_{l_{p l}}\left(\frac{1}{r}-\frac{1}{r_{y}}\right) d l=\int_{l_{p l}} \frac{\varepsilon_{s}-\varepsilon_{s y}}{d-x} d l
$$

$\Theta_{p l}$ - plastic rotation capacity

$I_{p \mid}$ - length of the plastic hinge

$1 / r$ - total curvature

$1 / r_{y}-$ yielding curvature

$\varepsilon_{\mathrm{s}}$ - total strain of steel reinforcement

$\varepsilon_{\text {sy }}$ - yielding strain of steel reinforcement

$d$ - effective depth of a cross-section

$x$ - neutral axis depth

Computing the rotation in critical regions can be a difficult task since the curvature has a discontinuous development along the beam axis due to bending stiffness difference between cracked sections and uncracked sections. On the other hand, in the plastic hinge region and near failure, the assumption of plane sections is not valid. This makes difficult determining the rotation by integrating the curvature along the beam axis.

The contribution of the concrete between cracks on the tensile strength originates a significant variation of the bending stiffness, known as tension stiffening effect. Disregarding this effect may lead to unrealistic predictions, i.e., if only the curvature in a fully cracked section is considered, a value greater than the actual rotation would be obtained (Figure 1).

According to EC2 [9] and others codes, the mean curvature must be computed by considering both uncracked and entirely cracked states, i.e., by applying Equation 2.

$$
(1 / \mathrm{r})_{\mathrm{m}}=\zeta \cdot(1 / \mathrm{r})_{\mathrm{II}}+(1-\zeta) \cdot(1 / \mathrm{r})_{\mathrm{I}}
$$

$(1 / r)_{m}$ - mean curvature

$(1 / r)_{1}$ - curvature at an uncracked section
$(1 / r)_{11}$ - curvature at a fully cracked section

$\zeta$ - distribution coefficient which take into account the tension stiffening effect

In a reinforced concrete member, the tensile reinforcement strain is variable along the beam axis. Consequently, the plastic rotation has also a discontinuous variation, depending essentially on the curvature of the cracked sections and, in less extent, on the curvature of the sections between cracks. In Figure 2, the diagonally dashed area corresponds to the integral of the plastic curvature along the plastic hinge length, i.e., to the plastic rotation.

In Figure 2 it is also observed that the plastic curvature tends to localize in cracked sections. Based on this, Bachmann, 1967 [10] proposed a straightforward method for computing the rotation in certain regions of beams due to cracks (rotation between the two opposite surfaces of the crack). The main characteristic of this method is the fact of not obtaining the rotation from the curvature. To apply this model it is necessary to know the number of cracks in the region of interest and the width and depth of the neutral axis at each crack [11-12]. In this case, photogrammetry and image processing are excellent techniques to obtaining all required data.

The model is based on a discrete analysis of the reinforced concrete member, being the tangent to the deformed beam discontinuous at each crack. Figure 3 exemplifies this procedure for a region with negative moments, where the total rotation is equal to the sum of the rotations in the ' $n$ ' existing cracks.

$$
\theta_{i}=\frac{w_{i}}{d-x_{i}}
$$

$$
\theta=\sum_{1}^{n} \theta_{i}
$$

Figure 3 - Bachmann's method for computing the rotation (example of a region over a support) (11-12)
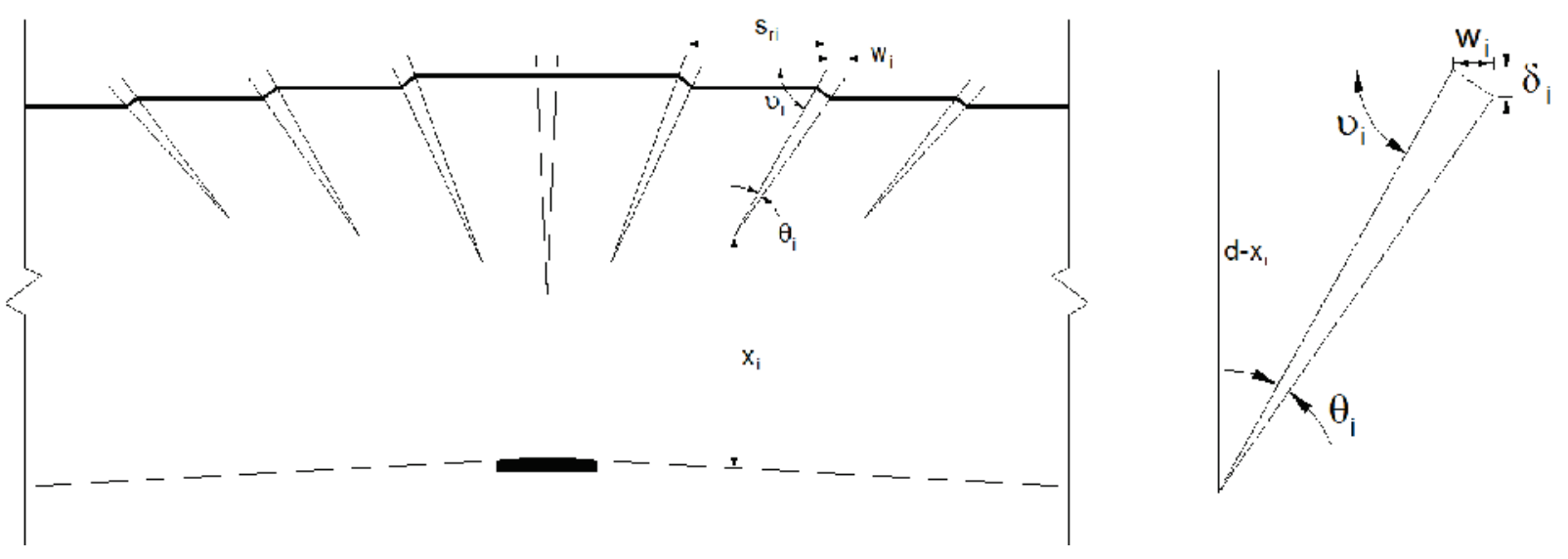
$w_{i}$ - i-th crack width

$d$ - effective depth of the cross-section

$\mathrm{xi}$ - neutral axis depth

$\Theta$ - rotation

\section{Photogrammetry and image processing}

\subsection{Photogrammetry}

Photogrammetry allows measuring the displacement field at targets placed at the surface of the specimen [1-4]. Alternatively, advanced image correlation techniques can be applied to avoid the use of pre-defined targets. In both cases, after obtaining the displacement field, the strain field is computed applying standard finite element method (MEF) procedures [5].

All operations performed after image acquisition to obtain the strain field, are described in this section, i.e.: i) target detection, where the positions of all targets are identified in all images; ii) homography, which allows scaling and orientating all images and thus obtaining the coordinates of the targets in the surface of the specimen; and iii) mesh generation, where a Delaunay triangulation is applied to define the post-processing mesh [13].

The first step, target detection, is performed using the Hough transform [14] to identify the geometrical center of the targets, at all stages. In summary, the average pixel radius allows computing a parametric transform, which results in a map of peaks coincident with the geometrical center of the targets $[14,15]$. Secondly, after detecting all targets, their position is obtained in the world coordinate system. Since all displacements are expected to occur within a plane, a simple homography is established to match image coordinates with real plane coordinates. The concept is accomplished by solving the following system of equations for the reference stage:

$\mathbf{A} \mathbf{h}=\left(\begin{array}{ccccccccc|c|}x_{1} & y_{1} & 1 & 0 & 0 & 0 & -x_{1} X_{1} & -y_{1} X_{1} & -X_{1} \\ 0 & 0 & 0 & x_{1} & y_{1} & 1 & -x_{1} Y_{1} & -y_{1} Y_{1} & -Y_{1} \\ x_{2} & y_{2} & 1 & 0 & 0 & 0 & -x_{2} X_{2} & -y_{2} X_{2} & -X_{2} \\ 0 & 0 & 0 & x_{2} & y_{2} & 1 & -x_{2} Y_{2} & -y_{2} Y_{2} & -Y_{2} \\ \vdots & \vdots & \vdots & \vdots & \vdots & \vdots & \vdots & \vdots & \vdots \\ x_{n} & y_{n} & 1 & 0 & 0 & 0 & -x_{n} X_{n} & -y_{n} X_{n} & -X_{n} \\ 0 & 0 & 0 & x_{n} & y_{n} & 1 & -x_{n} Y_{n} & -y_{n} Y_{n} & -Y_{n} \\ h_{3} \\ h_{4} \\ h_{2} \\ h_{5} \\ h_{5} \\ h_{n} \\ h_{7} \\ h_{5} \\ h_{9}\end{array}\right)=\mathbf{0} \quad$ (5)

where $X_{i}$ and $Y_{i}$ are the real plane coordinates for each target ' $i$ ' provided by the reference grid size painted at the surface of the specimen (in this case $20 \times 20 \mathrm{~mm}^{2}$ ), $x_{i}$ and $y_{i}$ are the corresponding coordinates in the image, and $h_{1}$ to $h_{9}$ are the homography parameters. Thus, the following relation can be written, for any point belonging to the surface of the specimen [16]:

$$
\left\{\begin{array}{l}
X \\
Y \\
1
\end{array}\right\}=\omega\left[\begin{array}{lll}
h_{9} & h_{2} & h_{3} \\
h_{4} & h_{5} & h_{6} \\
h_{7} & h_{8} & h_{9}
\end{array}\right]\left\{\begin{array}{l}
x \\
y \\
1
\end{array}\right\}
$$

where $\omega$ is a scale factor

Since only the ratio of the homography parameters is relevant, the number of unknowns to be solved is eight. Therefore, an exact solution is obtained using four targets. Usually, there are many more targets available and the resulting system is over determined. In this case, the solution is obtained by minimizing the norm $|\mathbf{A h}|$ of Equation 5 for ' $n$ ' points. The eigenvector corresponding to the least eigenvalue of $\mathbf{A}^{T} \mathbf{A}$ allows to directly obtaining the solution.

It should be noted that the homography define a map between two planes, independently of their position and orientation. The homography parameters can then be used to compute the real plane coordinates for all the targets and at any stage evaluated.

The differences in the coordinates in relation to the reference stage allow to directly computing the corresponding displacement field. Then, an auxiliary mesh is assembled by means of a Delaunay triangulation and using the reference targets [13]. Lastly, the strain field is directly computed by a strain-nodal displacement matrix associated to the auxiliary mesh (see [3] for more details).

It should be mention that all acquired images were orientated and scaled to 1:5 using the homography parameters. This value is used since the mean resolution of the original image frames was circa $0.2 \mathrm{~mm} /$ pixel. Later, the value is also used to measure the crack width (see Section 5.3).

\subsection{Image processing}

Digital image processing is a technique which allows detecting discontinuities in the image, i.e, points where sudden changes in the intensity level of the pixels occur. Therefore, detecting and measuring cracks on concrete surfaces is enabled. In the most cases, the detection of discontinuities in an image was performed by applying edge detectors [6-8]. This allows obtaining a binary image which enhances the crack pattern to be characterized. However, the method presents results strongly dependent on the surface conditions (other source of discontinuities). Thus, surfaces need to be carefully prepared and to adequate lighting conditions have to be assured. Therefore, combined approaches have emerged, in which the strain field is used to define critical regions where image processing is performed [15]. In this section, a brief description of the digital image processing operations required to enhance and measure cracking is presented. The surface of the specimen was painted white in order to obtain a homogeneous background, thus further enhancing cracking appearing during the experimental test. This method was developed for monitoring cracking by combining digital image processing and mathematical morphology operations, and a complete description of the procedure, including experimental examples, can be found in [7]. After orientating and scaling all the images according to the previous Section, the procedure comprises the following main steps: i) binarization of the images using the Otsu's method; ii) mathematical morphology operations (cleaning, linking and filling) in order to prevent other sources of discontinuities (e.g. surface imperfections) to be misleadingly taken as cracks; and finally iii) measuring any selected crack on the scaled image.

\section{Experimental program}

\subsection{Overview}

The method was applied to monitoring an experimental test un- 
Figure 4 - Cross section, structural scheme, shear force and bending moment diagrams
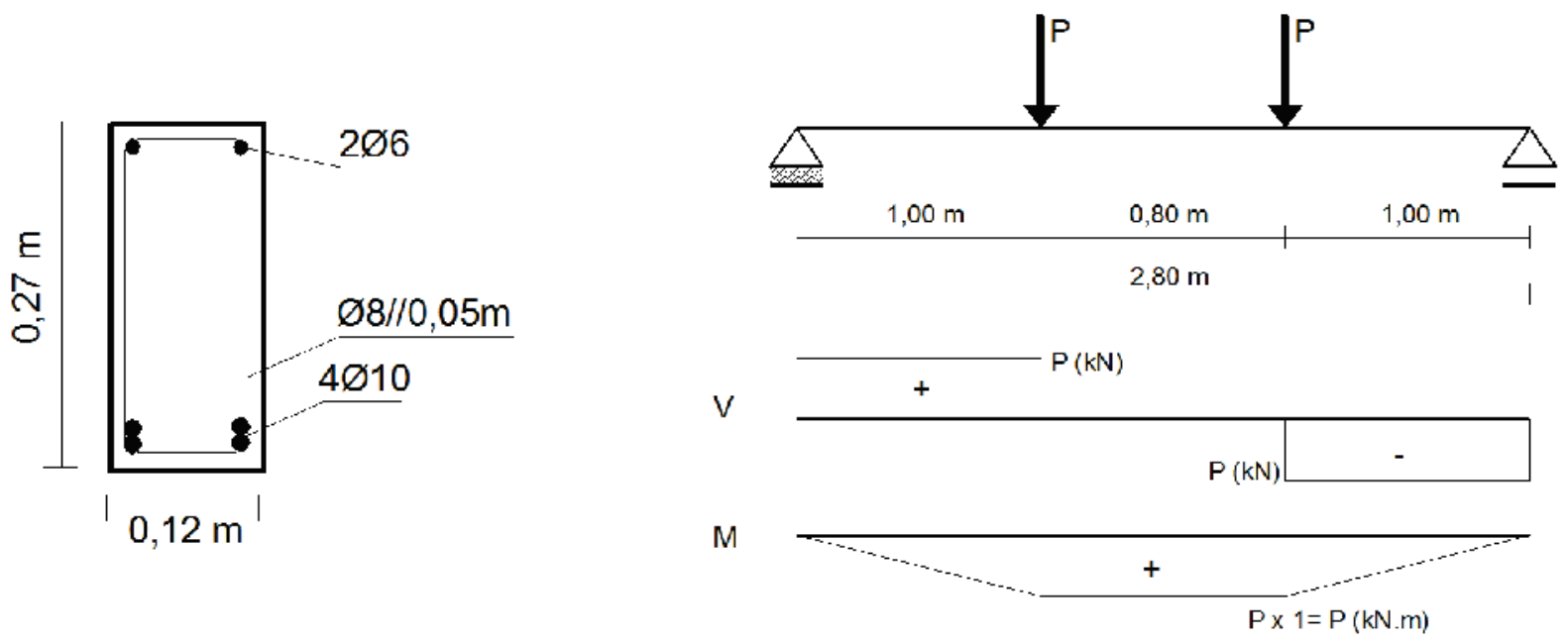

til failure of a reinforced concrete beam with $3.0 \mathrm{~m}$ long, $12 \mathrm{~cm}$ width and $27 \mathrm{~cm}$ height. The beam was produced with lightweight concrete with a density of $1900 \mathrm{~kg} / \mathrm{m}^{3}$, an average compressive strength of $51 \mathrm{MPa}$ at 28 days and $54 \mathrm{MPa}$ at the test day (166 days after casting) [17-18]. The concrete Young's modulus of $24 \mathrm{GPa}$ was also experimentally measured. For the longitudinal and transversal reinforcement hot rolled and ribbed steel bars of
S500NR-SD class were used. Tensile tests were performed to measure the steel yielding stress, $\mathrm{f}_{\mathrm{sym}}$, and the tensile strength, $\mathrm{f}_{\text {sum }}, 545$ and $645 \mathrm{MPa}$, respectively.

The beam was simply supported at both edges, $2.8 \mathrm{~m}$ span, and was subject to symmetrical loading, one concentrated load $\mathrm{P}$ which was divided into two equal loads distanced $1.0 \mathrm{~m}$ from the supports. Thus, the central region of the beam was theoretically under pure bending

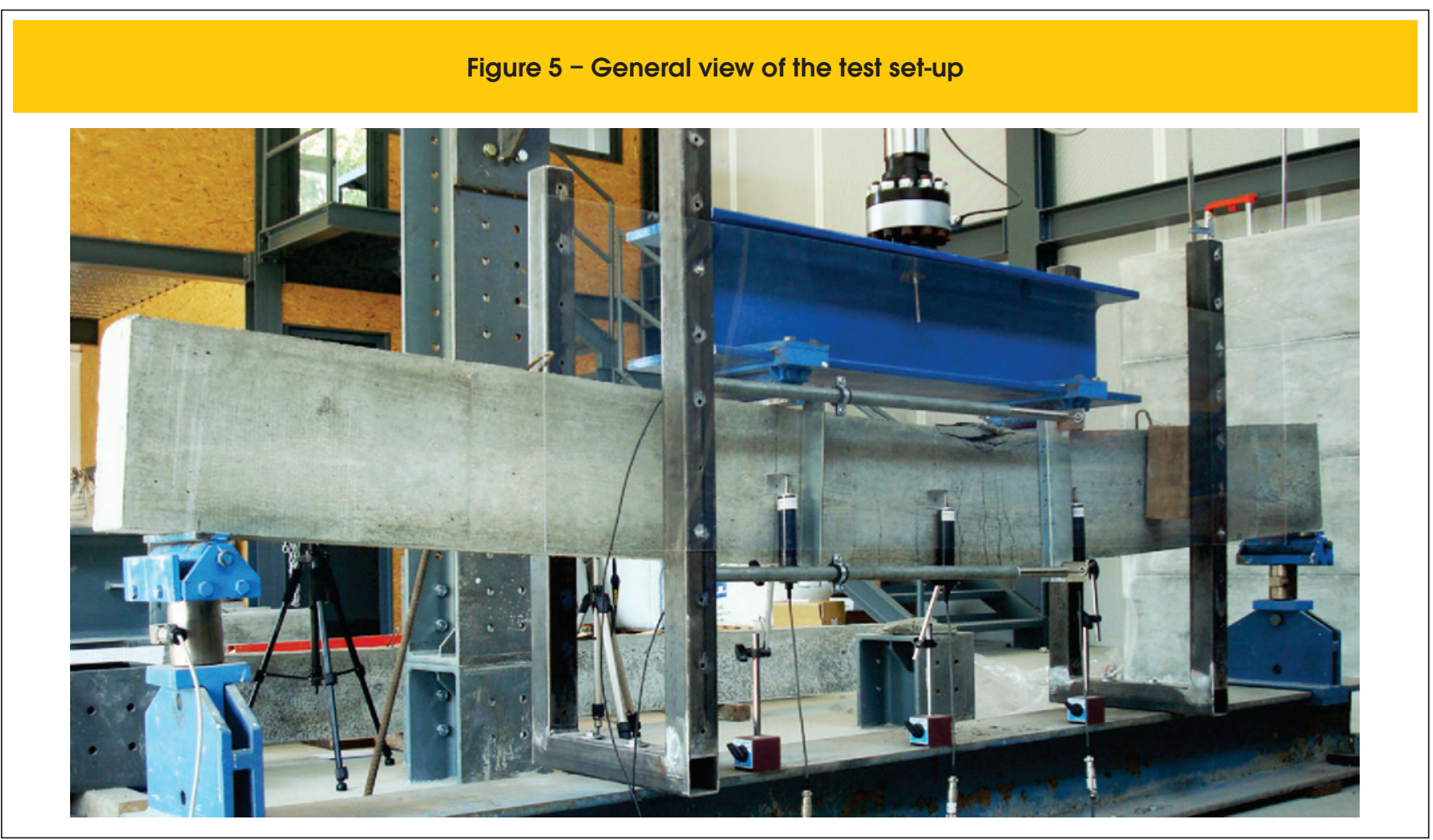




\section{Figure 6 - Force vs. testing time duration}

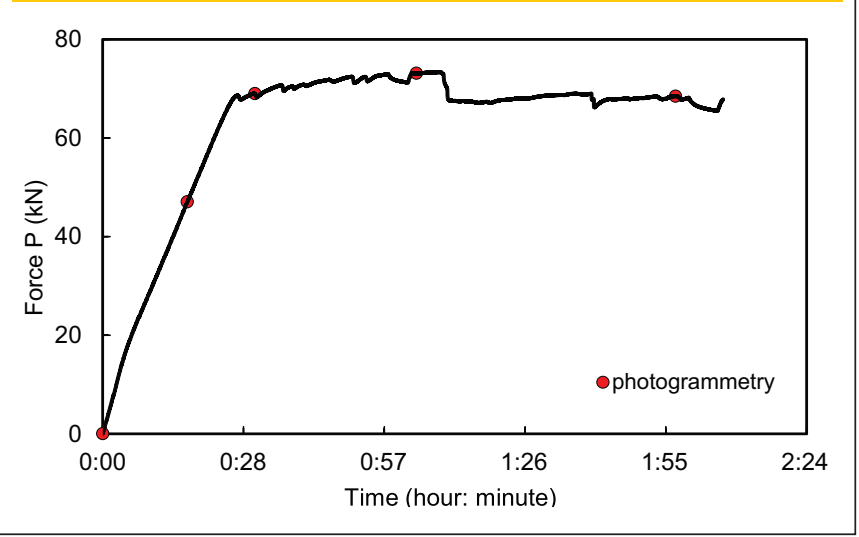

(Figure 4). The main load was applied by a $300 \mathrm{kN}$ capacity hydraulic servo-actuator, attached to the metallic support frame. The test was performed using displacement control at a constant rate of $0.01 \mathrm{~mm} / \mathrm{s}$. Several parameters were measured during the test to characterize the beam behavior, namely, support reactions and displacements at selected critical sections. The test was also monitored using the image processing methods described in Section 3 and traditional instrumentation, in particular, load cells under the supports and displacement transducers (LVDTs) placed in the pure bending region. Three LVDTs were used to measure vertical displacements, two placed at $1.0 \mathrm{~m}$ from each support (sections where loading was applied) and the third was placed exactly at mid-span. Two LVDTs were also placed to measure the horizontal stretching of the beam at the pure bending region (Figure 5).

\subsection{Preparation and image acquisition}

Previously works using photogrammetry and image processing in structural monitoring have shown that the precision obtained in the displacement field is typically better than $0.050 \mathrm{~mm}$. Thus, in order to measure a uniform strain field with $0.5 \%$ precision (value suitable for characterizing the crack formation) a minimum distance between targets of $20 \mathrm{~mm}$ is required (Dias-da-Costa et al. [3]). Therefore, the circular targets were painted in the surface of the specimen composing a square grid with sides of $20 \mathrm{~mm}$ length, oppositely to the surface used for placing the traditional instruments. All images were captured by a digital camera installed in front of the beam, at a distance of $1.75 \mathrm{~m}$. A tripod and a remote shutter were used to trigger the camera without compromising the stability. The images were acquired at full resolution of $4608 \times 3072$ pixel. Before start loading, ten images were sequentially acquired and later on used for scaling and orientating all images used to monitoring the experimental test and also for estimate the error in the results. Four stages of the test are herein analyzed (Figure 6).

\subsection{Error analysis}

As previously mentioned the ten images acquired before start loading were used to estimate the error of the results, namely: i) the error of the homography; and ii) the precision of the coordinates at each target. In the first case, the error was $0.236 \mathrm{~mm}$ and

\section{Figure 7 - Error map of target detection in the monitored surface}
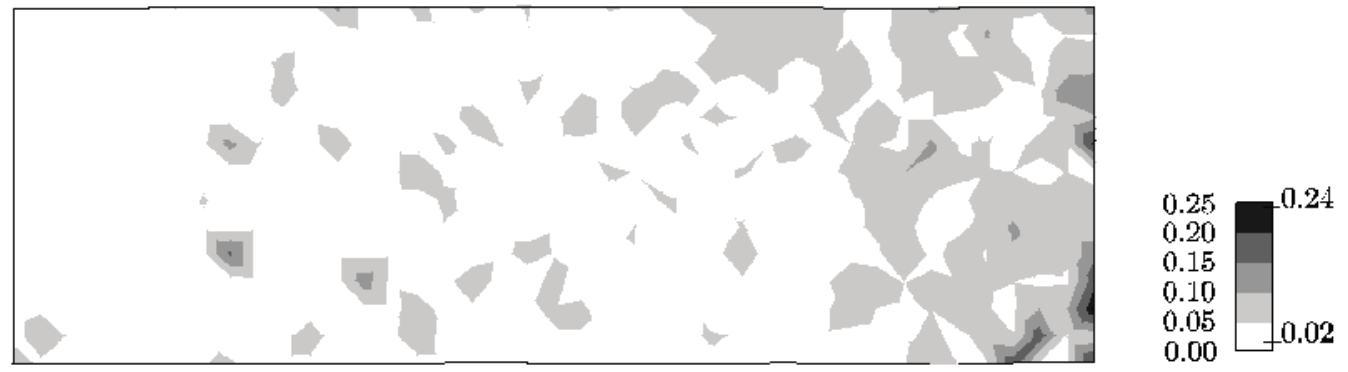

Table 1 - Vertical displacements in $\mathrm{mm}$ using LVDTs and photogrammetry (units in $\mathrm{mm}$ )

\begin{tabular}{|c|c|c|c|c|c|c|}
\hline & \multicolumn{2}{|c|}{ Section $1.0 \mathrm{~m}$ at the left support } & \multicolumn{2}{|c|}{ Section at mid-span } & \multicolumn{2}{|c|}{ Section $1.0 \mathrm{~m}$ at the right support } \\
\hline & Photog. & LVDT-1 & Photog. & LVDT-2 & Photog. & LVDT-3 \\
\hline Stage 1 & 9.60 & 8.68 & 10.62 & 9.69 & 8.98 & 9.62 \\
\hline Stage 2 & 17.14 & 15.97 & 19.65 & 18.31 & 17.12 & 18.05 \\
\hline Stage 3 & 33.55 & 32.57 & 40.09 & 39.21 & 34.89 & 35.81 \\
\hline Stage 4 & 60.49 & 67.27 & 78.77 & 83.13 & 74.18 & 72.10 \\
\hline
\end{tabular}




\section{Figure 8 - Cracks pattern and strain map (stage 3)}

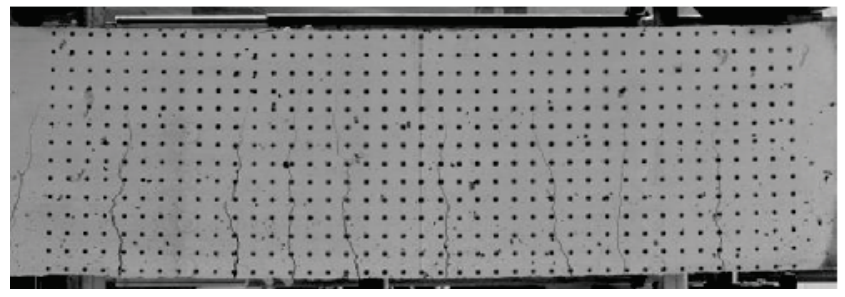

A Cracks pattern
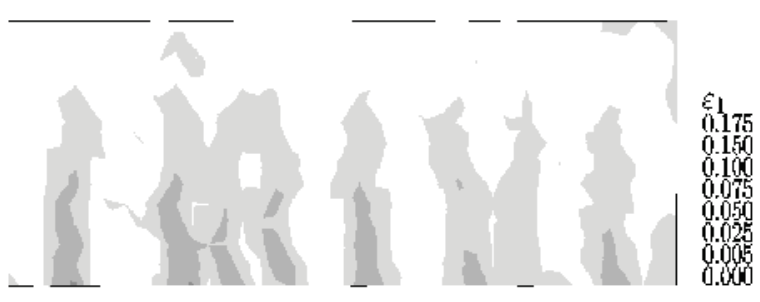

0.054

B First principal strain map
$0.315 \mathrm{~mm}$ in average and at a $95 \%$ confidence level, respectively. The precision in target detection was $0.031 \mathrm{~mm}$ and $0.046 \mathrm{~mm}$ in average and at a $95 \%$ confidence level, respectively (Figure 7 ). It is important to highlight that the error of the homography is a systematic error, i.e, the error on the displacement is assumed to correspond to the error in the target detection. Finally, the error in the strain field was circa $0.3 \%$ for the defined grid spacing.

\section{Results analysis}

\subsection{Preliminary results}

The vertical displacements obtained using photogrammetry were compared with those obtained by traditional monitoring. The obtained differences were relatively small, $6 \%$ on average (Table 1 ). From the displacements measured at each target it is possible to compute the strain field (see Section 3.1). In Figure 8, the first principal strain field at stage 3 is shown (see Section 3.2). It is highlighted that it is consistent with the existing cracking pattern. Additionally, image processing can be used to measure the crack width at each test stage. This information is later used to determine the rotation in Section 5.3.

\subsection{Curvature}

The mean curvature at the pure bending region can be defined using the parabolic equation that best fits the vertical displacements. The curvature is the directly computed by the 2 nd derivative of the equation. For this purpose, photogrammetry presents a significant advantage because it allows recording the displacement at a large number of cross sections which can be used to obtain a reliable approximation of the parabolic equation.

The average curvature can also be assessed by measuring the horizontal stretching at the pure bending region. As mentioned above, two horizontal LVDTs were used to measure these deformations. Knowing the vertical distance between the LVDTs axis and the horizontal distance between reading points, the average strains and corresponding curvature, can be computed. In Figure 9, the moment versus curvature relation for the pure bending region $(800 \mathrm{~mm})$ is shown, identifying the onset of reinforcement yielding, stage 3 and stage 4 .

The curvature for a specific section and at a particular stage is determined based on strains measured along the section height. Initially, it is necessary to define the best fit straight line to the strains. Figure 10 presents the strain evolution and the corresponding curvature comput-

\section{Figure 9 - Bending moment vs. average curvature measured using horizontal LVDTs}

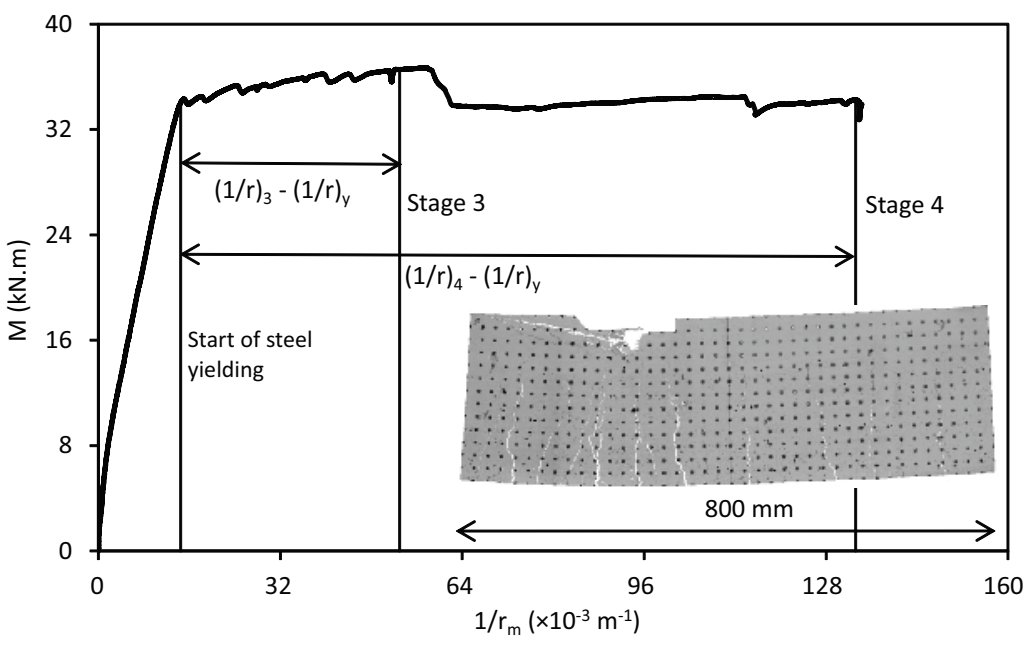


Figure 10 - Curvature at a section placed at $50 \mathrm{~mm}$ of the left edge in the pure bending span

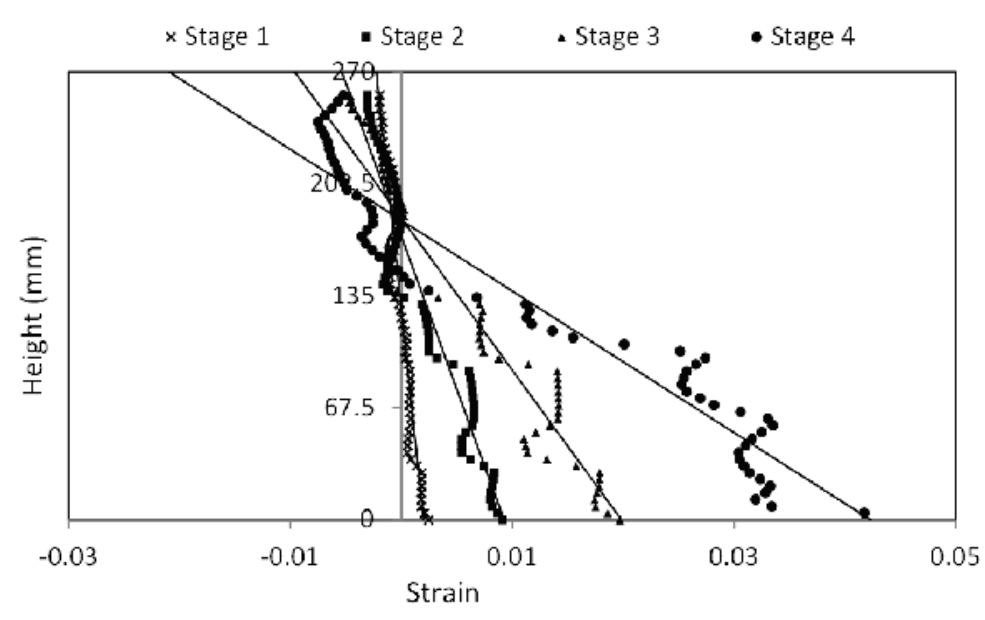

$1 / \mathbf{r}=\lg |\cdot / 2-\operatorname{arc} \lg (m)|=1 / \mathrm{m}$

Stage 1

y $63099 x-128$

$1 / \mathbf{r} 0.016 \times 10^{3} \mathrm{~m}^{1}$

Statye 2

$\mathrm{y}=-18171 \mathrm{x} \quad 171$

$1 / \mathbf{r}=0.051 \times 10^{-3} \mathrm{~mL}^{-1}$

Stags 3

$y=-9172 x-182$

$1 / \mathrm{r} \quad 0.109 \times 10^{-3} \mathrm{~m}^{-1}$

Stage 1

y $4266 \mathrm{x}-181$

$y \quad 4266 \mathrm{x}-181$
$1 / \mathrm{r}=0.231 \times 10^{3} \mathrm{~m}^{1}$

Strain

Figure 11 - Curvature along the pure bending span $(800 \mathrm{~mm})$
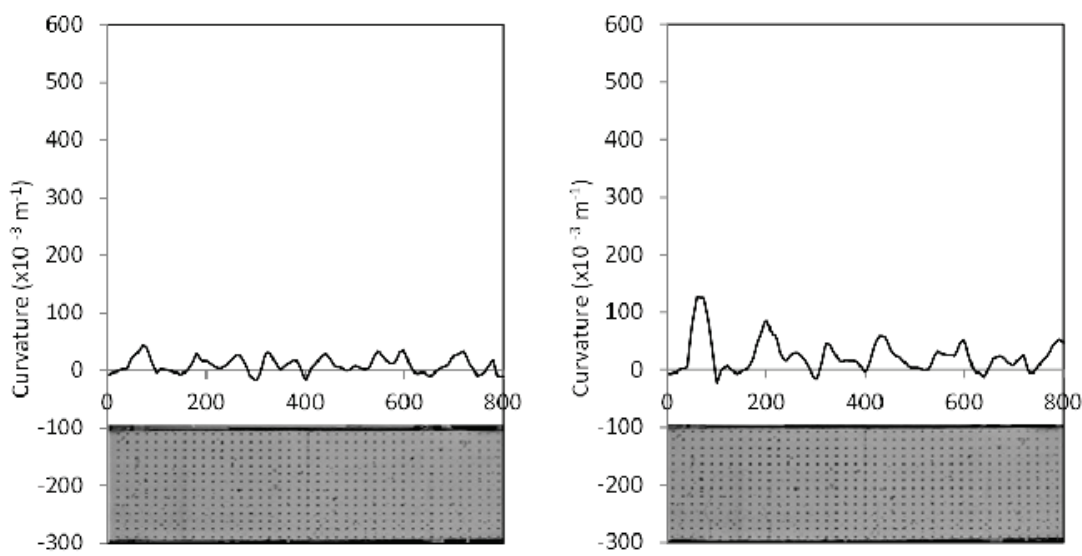

Stage 1

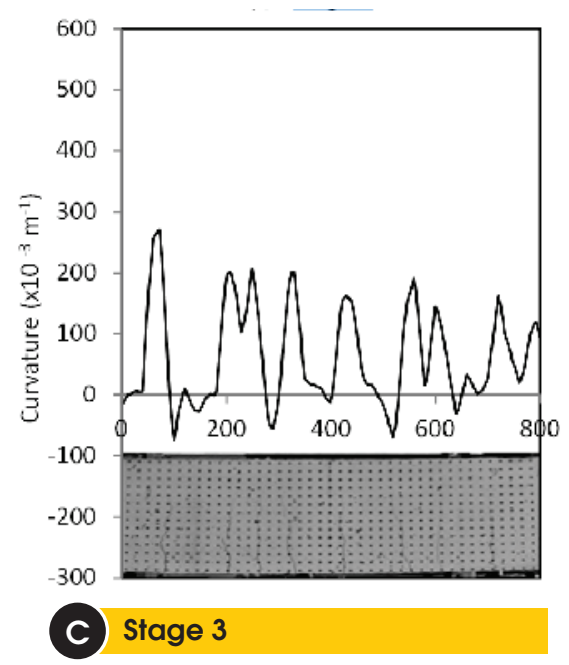

B Stage 2

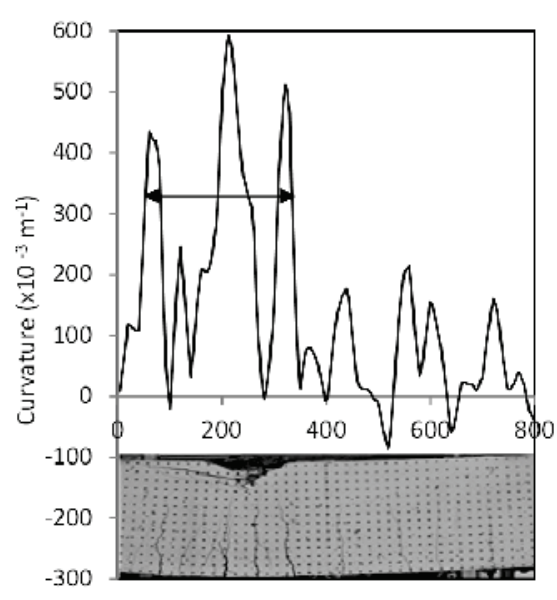

D Stage 4 
Figure 12 - Plastic rotation using method 1 with shaded area representing the plastic rotation

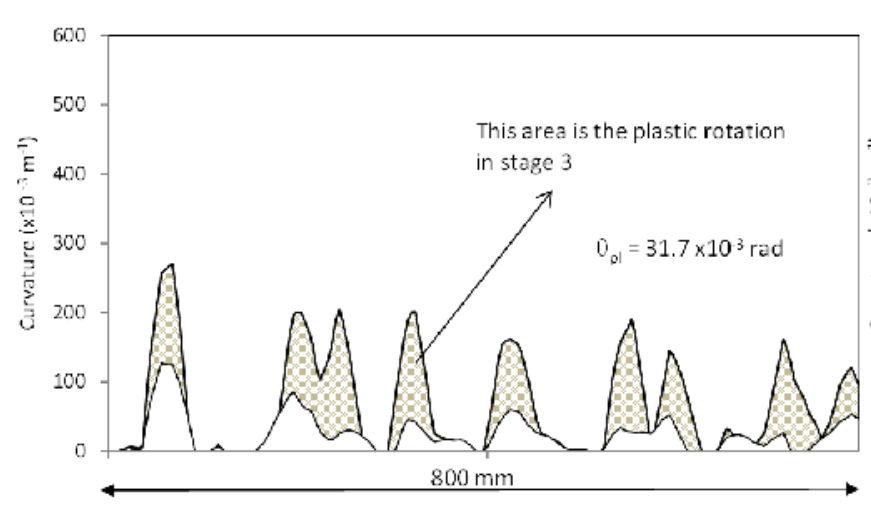

Stage 3

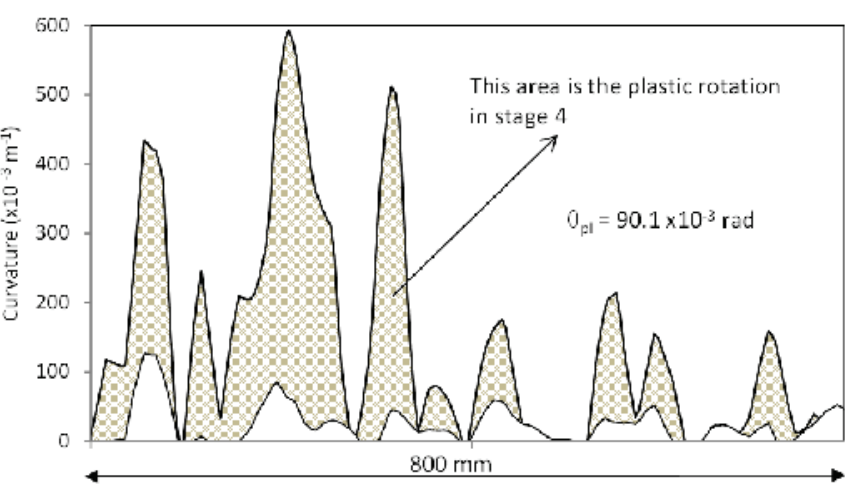

B Stage 4 ed for the four stages considered in this analysis. The selected section was placed at $50 \mathrm{~mm}$ from the left edge of the pure bending region. A perfect linearity between strains was not found because, during the deformation, the sections do not remain plain due to concrete cracking. It is reminded that mechanical strain gauges and demcs only allow obtaining the average curvature in lengths of 100 or $200 \mathrm{~mm}$ (values limited by the mechanical strain gauge length) and not curvature in a specific section (Carmo and Lopes [19]). Another disadvantage of using mechanical strain gauges compared with photogrammetry is the time required to perform all readings.

Photogrammetry provides a detailed curvature analysis because the spacing between targets can be significantly reduced, in this case $20 \mathrm{~mm}$ was adopted. The detailed evolution of curvature along the beam axis allows analyzing the influence of the concrete between the cracks and cracked sections in the beam deformation. Figure 11 presents the curvature evolution along the beam axis for the four analyzed stages, where it can be seen that the curvature is not constant. In stages 1 and 2, despite the cracks width not being very significant, a larger curvature was already detected in cracked sections. Between stages 2 and 3, the curvature increases in cracked sections, being approximately constant in sections between cracks. In stage 4 , it can be seen that sections with maximum cur- vatures tend to concentrate on a limited length, about 300-350 mm.

\subsection{Plastic rotation}

The reinforced concrete members have a nonlinear behavior when subjected to higher loads. Before reinforcement reaches the yield strength, the nonlinear behavior is caused by concrete cracking. After reaching the steel yielding, the influence of the nonlinearity of steel stress-deformation must also be taken into account. At this moment, it is considered that a plastic hinge is formed. To quantify the ductility of the member, the evaluation of the plastic rotation capacity at certain zones of the structure is generally used [20].

The plastic rotation capacity of a beam is the maximum plastic rotation supported immediately before collapsing. To compute the plastic rotation three methods are presented: i) curvature integration after steel yielding in the plastified area (Eq. 1 and Figure 12), ii) multiplying the difference of the average curvatures, at the steel yielding onset and at the analyzed stage, by $800 \mathrm{~mm}$ length (curvatures determined by the horizontal LVDTs) (Figure 9), iii) Bachmann's method, based on the sum of rotations which occur between the two sides of the crack (Eqs. 3 and 4 and Figure 13). The latter is easily applied using photogrammetry and image pro-

Figure 13 - Crack width and neutral axis depth in $\mathrm{mm}$ (stage 3)

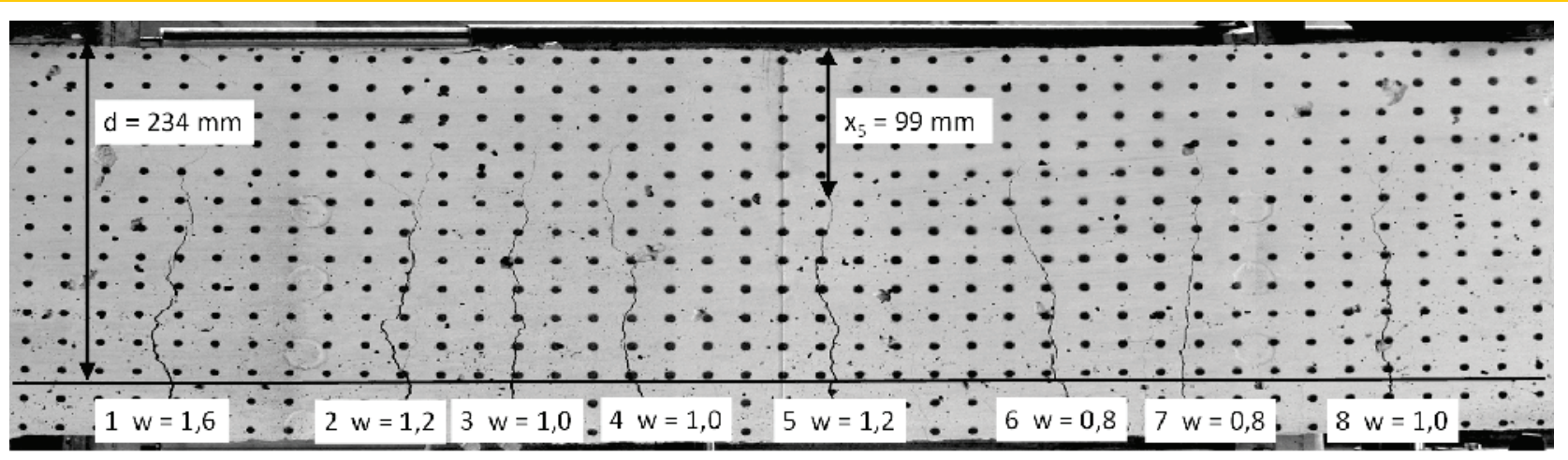




\begin{tabular}{|c|c|c|c|}
\hline \multicolumn{4}{|c|}{$\begin{array}{c}\text { Table } 2 \text { - Rotation computed in each } \\
\text { identified crack }\end{array}$} \\
\hline \multicolumn{4}{|c|}{ Stage 3} \\
\hline Crack & $x_{i}(m m)$ & $w_{i}(\mathrm{~mm})$ & $\Theta_{i}\left(\times 10^{-3} \mathrm{rad}\right)$ \\
\hline 1 & 86 & 1.60 & 1.60 \\
\hline 2 & 92 & 1.20 & 1.20 \\
\hline 3 & 100 & 1.00 & 1.00 \\
\hline 4 & 87 & 1.00 & 1.00 \\
\hline 5 & 99 & 1.20 & 1.20 \\
\hline 6 & 91 & 0.80 & 0.80 \\
\hline 7 & 109 & 0.80 & 0.80 \\
\hline \multirow[t]{2}{*}{8} & 120 & 1.00 & 1.00 \\
\hline & \multicolumn{2}{|c|}{$\Sigma \Theta_{i}(\times 10-3 \mathrm{rad})=$} & 63.2 \\
\hline
\end{tabular}

\begin{tabular}{|cc|}
\hline $\begin{array}{c}\text { Table } 3 \text { - Total rotation obtained } \\
\text { by Bachmann method }\end{array}$ \\
Stage & $\Theta_{\mathrm{i}}\left(\times 10^{-3}\right.$ rad $)$ \\
1 & - \\
2 & 19.5 \\
3 & 63.2 \\
4 & 123.5 \\
\hline
\end{tabular}

\begin{tabular}{|cccc|}
\hline \multicolumn{4}{|c|}{ Table 4 - Plastic rotation (x $10^{-3}$ rad) } \\
\hline Stage & Method 1 & Method 2 & Method 3 \\
\hline 3 & 31.7 & 30.8 & 43.7 \\
4 & 90.1 & 95 & 104 \\
\hline
\end{tabular}

cessing, since all required data can be easily measured after the test, thus not requiring to stop the test to perform readings (Tables 2 and 3). However, this method has a drawback: in stages before steel yielding, when cracks are relatively small, is not possible to achieve the required accuracy to measure the cracks width.

Table 4 summarizes the plastic rotations in pure bending region obtained by the three methods mentioned. It is found that the values obtained using methods 1 and 2 are very similar, with differences lower than $5 \%$, and with the values smaller than those obtained using method 3 , particularly at step 3 , where the differences can reach $40 \%$.

\subsection{Tension stiffening effect evaluation}

The beam flexural stiffness (EI) decreases as the applied load increases, initially due to concrete cracking and, at a later stage, due to the reinforcement yielding. Theoretically, flexural stiffness in a specific section can be determined in state I and II: in state I the whole cross-section of concrete and steel is considered, whereas in state II only the concrete under compression and, obviously, the steel area are considered. The flexural stiffness experimentally measured should be between these two limits due to the tension stiffening effect. Figure 14 presents the evolution of flexural stiffness (EI) with the applied load, P. The latter parameter is written using the dimensionless ratio $P / P_{y}$ (where $P_{y}$ is the load required to the reinforcement yielding). The stiffness was measured using the relation between bending moment applied and mean curvature, in this case measured using the horizontal LVDTs. Initially, stiffness assumes high values because the curvature is very low and therefore very sensitive to any reading variation from the LVDTs.

The tension stiffening effect is particularly important in the analysis of deformations in concrete structures under serviceability conditions, as recommended in design codes for concrete structures. As mentioned in Section 2, the distribution coefficient $z$ considers the contribution of the tension stiffening effect. An analysis of this effect is provided below to stage 1 , where the applied load is ap-

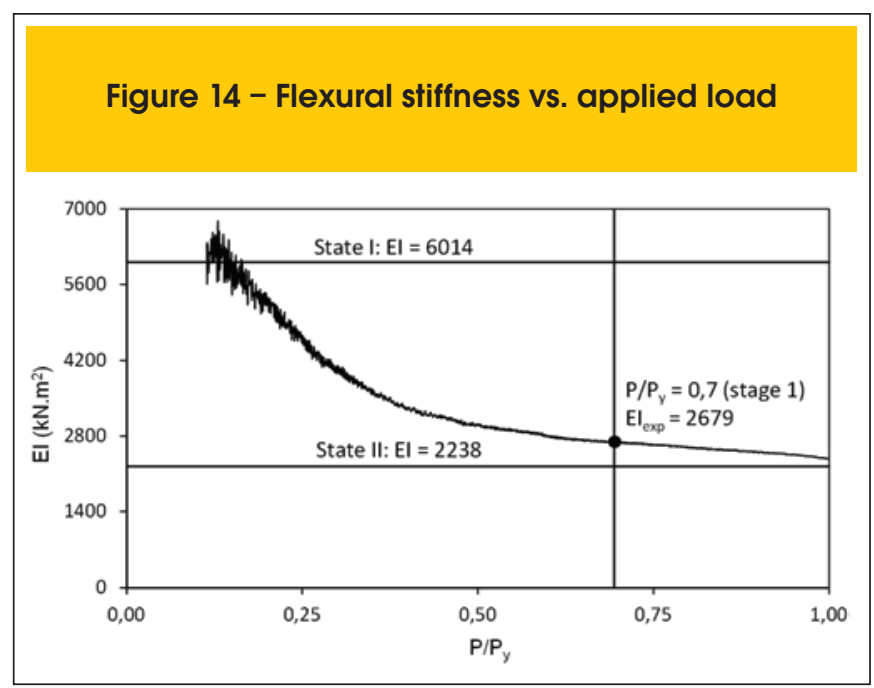

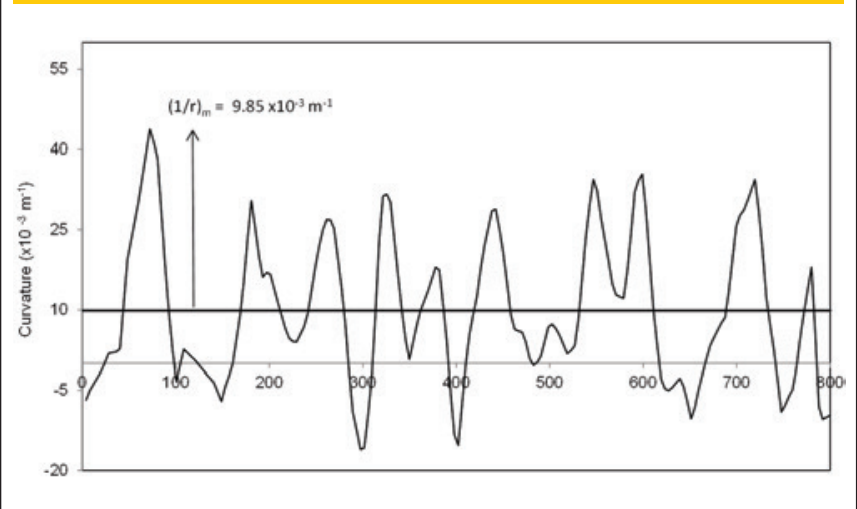


proximately $70 \%$ of the maximum load, which corresponds roughly to serviceability conditions.

Considering the flexural stiffness value experimentally obtained, i.e. $2679 \mathrm{kN} . \mathrm{m}^{2}$, and applying Equation 2 is obtained a value for the distribution coefficient $\zeta$ of 0.883 . This coefficient can also be determined using the curvature computed by photogrammetry and image processing. At this stage the bending moment is $23.5 \mathrm{kN}$. m. Knowing the stiffness in states I and II, the curvature is: $(1 / \mathrm{r})$ $\times 10^{-3} \mathrm{~m}^{-1}$ and $(1 / \mathrm{r})_{\|}=10.5 \times 10^{-3} \mathrm{~m}^{-1}$. Since the average curvature, in the analyzed region, is $9.85 \times 10^{-3} \mathrm{~m}^{-1}$, the distribution coefficient $\zeta$ is 0.902 (Figure 15). The values experimentally measured can be compared with the EC2 [9], $\zeta=1-\beta .\left(\mathrm{M}_{\mathrm{cr}} / \mathrm{M}\right)^{2}$. In this case, $\beta$ is 1 (short-term loading) and the cracking moment $M_{c r}$ is $6 \mathrm{kN} \cdot \mathrm{m}$, considering the concrete tensile strength and all homogenized section. Taking into account this data, and according the EC2, the distribution coefficient value is 0.935 , very close to the values obtained experimentally.

\section{Conclusions}

Recently, innovative methods for monitoring structures using photogrammetry and image processing have been developed. This paper presents a practical example of these techniques, namely, in the characterization of the structural behavior of reinforced concrete beams, with particular attention in plastic rotation and tension stiffening effect.

Photogrammetry and image processing were used to monitor a large number of points on a concrete surface until failure. Four stages during the experimental test were analyzed, highlighting the interest in the developed tools, which allow the computation of the strain field on concrete surfaces and characterization of the cracking pattern. Throughout the test, similar values of the vertical displacements between photogrammetry and LVDTs were obtained. The detailed information of the strain field in the concrete surface allowed computing the curvature in specific sections and evaluating their progress along the beam axis. This information is extremely difficult to obtain with traditional methods, since the use of mechanical strain gauges is required. Usually, the mean curvature along regions can only be determined with 100 or $200 \mathrm{~mm}$ resolution due to the limitation of the equipment size. Photogrammetry allows obtaining the curvature along smaller regions, in this case with $20 \mathrm{~mm}$ length. The detailed evolution of the curvature along the beam axis was used to study the plastic rotation and the tension stiffening effect. The method allowed to experimentally verify that the plastic curvature was localized in cracked sections and in a restricted length of the beam, in this case around $350 \mathrm{~mm}$. Photogrammetry was also used to determine rotation between the cracks boundaries. These values have also been used to compute the plastic rotation in the pure bending zone.

In summary, the presented study aims validating and demonstrating that photogrammetry and image processing techniques can provide significant and relevant data relatively to traditional methods of monitoring, both in serviceability and in ultimate states. Furthermore, due to the amount of data recorded, is possible to perform analyses that would otherwise be unfeasible.

\section{Acknowledgments}

The authors would like to express their gratitude to the Department of Civil Engineering of the Polytechnic of Coimbra for providing the conditions to carry out this study and the colleagues Hugo Costa, Tiago Simões, Cátia Lourenço and Diogo Andrade, for their collaboration in the experimental programme.

\section{References}

[01] Hegger J, Sherif A, Görtz S (2004) Investigation of pre-and postcracking shear behavior of prestressed concrete beams using innovative measuring techniques. ACI Structural Journal 101 (2):183-192.

[02] Lange J, Benning W, Siering K Crack detection at concrete construction units from photogrammetric data using image processing procedures. In: ISPRS Commission VII Mid-term Symposium Remote Sensing: From Pixels to Processes, Enschede, Netherlands, 8-11 May 2006. pp 493-496.

[03] Dias-da-Costa D, Valença J, Júlio E (2011) Laboratorial test monitoring applying photogrammetric post-processing procedures to surface displacements. Measurement 44 (3):527-538.

doi:10.1016/j.measurement.2010.11.014.

[04] Valença J, Júlio E, Araújo H (2012) Application of photogrammetry to structural assessment. Experimental Techniques 36 (5). doi:10.1111/j.1747-1567.2011.00731.x

[05] Hoffman ME, Manevitz LM, Wong EK, Geers MGG, De Borst R, Brekelmans WAM (1996) Computing strain fields from discrete displacement fields in 2D-solids. International Journal of Solids and Structures 33 (29):4293-4307. doi:10.1016/0020-7683(95)00240-5

[06] Abdel-Quarter I, Abudayyeh O, Kelly M (2003) Analysis of edge detection techniques for crack identification in bridges. Journal of Computing in Civil Engineering 17 (3):255-263. doi:10.1061/ ASCE!0887-3801 2003!17:4 255!

[07] Valença J, Dias-da-Costa D, Júlio ENBS (2012) Characterisation of concrete cracking during laboratorial tests using image processing. Construction and Building Materials 28 (1):607-615. doi:10.1016/j.conbuildmat.2011.08.082

[08] Hutchinson TC, Chen Z (2006) Improved Image Analysis for Evaluating Concrete Damage. Journal of Computing in Civil Engineering 20 (3):210-216

[09] CEN (2004) EN 1992-1-1: Eurocode 2: Design of Concrete Structures - Part 1-1: General Rules and Rules for Buildings, in: European Committee for Standardization (CEN).

[10] Bachmann H (1967) Zur plastizitätstheoretischen Berechnung statisch unbestimmter Stahlbetonbalken. Technische Hochschule, Zürich

[11] Park R, Paulay T (1975) Reinforced concrete structures. Wiley, New York.

[12] Buchaim R (2001) A influência da não-linearidade física do concreto armado na rigidez à flexão e na capacidade de rotação plástica. São Paulo University.

[13] Barber CB, Dobkin DP, Huhdanpaa H (1996)

The quickhull algorithm for convex hulls. ACM 
Transactions on Mathematical Software 22 (4):469-483. doi:10.1145/235815.235821.

[14] Ballard D (1981) Generalizing the Hough Transform to Find Arbitrary Shapes. Pattern Recognition 13:111-122

[15] Valença J, Dias-da-Costa D, Júlio E, Araújo H, Costa H (2012) Automatic crack monitoring using photogrammetry and image processing. Measurement (in press). doi:10.1016/j.measurement.2012.07.019.

[16] Criminisi A, Reid I, Zisserman A (2000) Single view metrology. Int J Comput Vision 40 (2):123-148. doi:10.1023/a:1026598000963.

[17] Carmo RNF, Costa H, Lourenço C, Andrade D, Simões $\mathrm{T}$ (2012) Influence of both concrete strength and transverse confinement on bending behaviour of reinforced LWAC beams. Engineering Structures (in press). doi:10.1016/j.engstruct.2012.09.030.

[18] EN 12390, Testing hardened concrete (2009). European Committee for Standardisation, Brussels, Belgium.

[19] Carmo RNF, Lopes SM (2005) Influence of the shear force and transverse reinforcement ratio on plastic rotation capacity. Structural Concrete, Journal of the fib (Thomas Telford Journal) 6 (3):107-117

[20] CEB (1998) Ductility of reinforced concrete structures. Bulletin d'Information $n^{\circ} 242$. Lausanne, Switzerland. 